\title{
micromachines
}

ISSN 2072-666X

www.mdpi.com/journal/micromachines

Article

\section{SU-8 Electrothermal Actuators: Optimization of Fabrication and Excitation for Long-Term Use}

\author{
Thomas Winterstein ${ }^{1, *}$, Matthias Staab ${ }^{1}$, Christian Nakic ${ }^{1}$, Hans-Jürgen Feige ${ }^{2}$, Jürgen Vogel ${ }^{2}$ \\ and Helmut F. Schlaak ${ }^{1}$
}

1 Microtechnology and Electromechanical Systems Laboratory, Institute of Electromechanical Design, Technische Universität Darmstadt, Merckstr. 25, 64283 Darmstadt, Germany; E-Mails:m.staab@emk.tu-darmstadt.de (M.S.); c.nakic@emk.tu-darmstadt.de (C.N.); schlaak@emk.tu-darmstadt.de (H.F.S.)

2 Laboratory of Experimental Solid and Micro Mechanics, Faculty of Automotive Engineering, Westsächsische Hochschule Zwickau, Dr.-Friedrichs-Ring 2A, 08056 Zwickau, Germany; E-Mails: juergen.vogel@fh-zwickau.de (J.V.); hans.juergen.feige@fh-zwickau.de (H.J.F.)

* Author to whom correspondence should be addressed; E-Mail: t.winterstein@emk.tu-darmstadt.de; Tel.: +49-6151-16-6281; Fax: +49-6151-16-4096.

External Editor: Ulrike Wallrabe

Received: 2 October 2014; in revised form: 14 November 2014 / Accepted: 21 November 2014 / Published: 2 December 2014

Abstract: In this paper we examine the suitability of SU-8 2000 as a construction material for electrothermal actuators and the actuator stability for long-term operation. The fabrication of SU-8 was optimized for mechanical and thermal stability. Samples with different softbake duration, exposure dose and postbake temperature were evaluated using Fourier-Transform IR-spectroscopy and dynamic-mechanical analysis. The exposure dose and postbake temperature proved to have a strong influence on the cross-linking and the glass transition temperature. A final hardbake levels the effects of the process history. A high degree of crosslinking, a low drop of the dynamic modulus over temperature (30\%) up to the glass transition temperature $100-140{ }^{\circ} \mathrm{C}$ were achieved for SU-8 with an exposure dose of $1500 \mathrm{~mJ} / \mathrm{cm}^{2}$, a postbake temperature of $95{ }^{\circ} \mathrm{C}$ and hardbake of $240{ }^{\circ} \mathrm{C}$. Electrothermal actuators proved to be stable until the end of the experiment after 2400 duty cycles. Actuator deflections up to $55 \mu \mathrm{m}$ were measured (actuator length: $4 \mathrm{~mm}$ ) for input powers up to $160 \mathrm{~mW}$ and a maximum operating temperature of $120^{\circ} \mathrm{C}$. Higher temperatures led to permanent deformations and failure. An offset drift of up to $20 \%$ occurs during actuation, but converges after a burn-in phase of about two hours. 
Keywords: electrothermal actuator; SU-8; long-term stability; pseudo-bimorph; glass transition temperature

\section{Introduction}

The electrothermal actuation principle is one of the principles, with increasing interest in the MEMS domain. Local heating and thereby thermal expansion of a beam-based geometry leads to defined deformation and to actuator deflection. Deflections $>100 \mu \mathrm{m}$ and forces $>100 \mathrm{mN}$ can be provided at an energy density higher than of electrostatic actuators. Electrothermal actuators can be fabricated from metal [1,2], silicon [3,4] or polymer materials such as epoxide, polyimide [5] or polyether ether ketone (PEEK) [6]. Applications of miniaturized thermal actuators are the positioning of optical fibers [7], micro grippers [3,8-10], relays [11,12], Radio Frequency (RF) switches [13] or miniaturized drives [14].

Actuators made of metal or semiconductor materials provide high thermal stability up to several hundreds of ${ }^{\circ} \mathrm{C}$, but low thermal expansion coefficients ( $\mathrm{Si}: 2.3 \mathrm{ppm} / \mathrm{K}$; Ni: $13 \mathrm{ppm} / \mathrm{K}$ ). This leads to very high operating temperatures and increased fabrication costs. Therefore a cost-efficient and low-temperature approach is pursued at the Institute of Electromechanical Design (EMK) at Technische Universität Darmstadt among others: The epoxy-based negative photoresist SU-8 2000 is used as structural material, featuring a high glass temperature of up to $240{ }^{\circ} \mathrm{C}$ and a large thermal expansion coefficient of $52 \mathrm{ppm} / \mathrm{K}$ [15]. The actuators can be fabricated using cost-efficient up-scalable technologies like UV-lithography and electroforming on low-cost substrates.

However, most of the devices known today are used in a laboratory environment and mainly for a very limited amount of operation time. To underline the potential of cost-efficient polymer electrothermal actuators for commercial use, their suitability and stability for hours of operation has to be examined. Staab observed rapid degradation of electrothermal actuators made of SU-8 depending on the input power [16]. Thus, in this paper we present the optimization and experimental analysis of the long-term stability of electrothermal actuators. First, the fabrication process is optimized to maximize mechanical stability of SU-8. Second, samples of actuators are characterized regarding electrical power consumption, maximum operation temperature and long-term operation.

\section{Actuator Design Approach and Fabrication Process Using Surface Micromachining}

\subsection{The Pseudo-Bimorph Actuator Design}

Figure 1a shows the pseudo-bimorph actuator design used in this paper. Two beams of $4 \mathrm{~mm} \times 350 \mu \mathrm{m} \times 300 \mu \mathrm{m}$ are placed in parallel, connected at their heads and thermally decoupled by an air gap of $150 \mu \mathrm{m}$. As the beams are made of a polymer and therefore unable to be heated directly, a metallic heater is attached to the outer beam to create local Joule heating. The heaters are laterally meandered to provide homogeneous heating and low mechanical stiffness in the direction of thermal expansion. The meander width is $20 \mu \mathrm{m}$. The longitudinal expansion of the outer beam is transformed into a rotation by the inner beam, creating the actuator deflection. As the movement occurs due to the 
temperature gradient between the outer and the inner beam, homogeneous heating of the whole system (e.g., rise of room temperature) does not lead to actuator deflection.

Figure 1. Polymer electrothermal pseudo-bimorph actuator: (a) Fabricated pseudo bimorph actuator with typical dimensions [17]. (b) Fabrication process: (1) Sacrificial layer: Structuring $15 \mu \mathrm{m}$ of laminated copper using wet etching. (2) Conductive seed layer: Sputtering of $200 \mathrm{~nm} \mathrm{Cu}$ for electroforming. (3) Heater I: Structuring the mold using $10 \mu \mathrm{m}$ of AZ 9260. (4) Heater II: Electroforming of $2 \mu \mathrm{m}$ Ni. (5) Conducting paths I: Structuring the mold using 30 $\mu \mathrm{m}$ of AZ 9260. (6) Conducting paths II: Electroforming of $20 \mu \mathrm{m}$ Ni. (7) Expansion body: Structuring of $300 \mu \mathrm{m}$ SU-8 2025 using UV-lithography. (8) Release: Wet etching of $\mathrm{Cu}$ sacrificial and seed layer using APDS $\left(\mathrm{NH}_{4} \mathrm{~S}_{2} \mathrm{O}_{8}+\mathrm{NH}_{3}+\mathrm{H}_{2} \mathrm{O}_{2}\right)$.

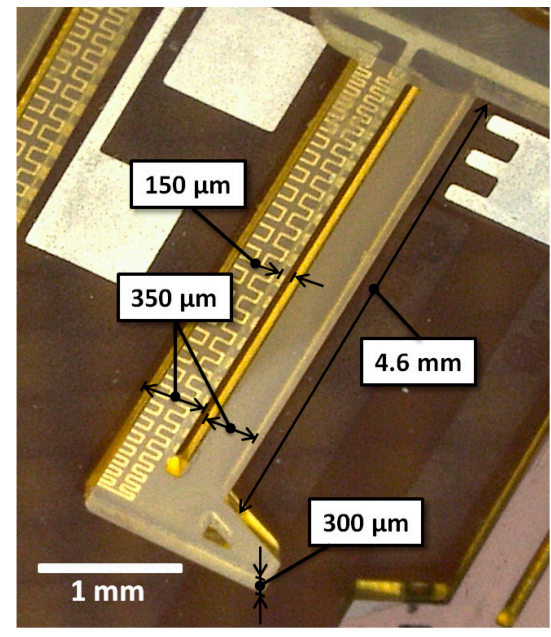

(a)

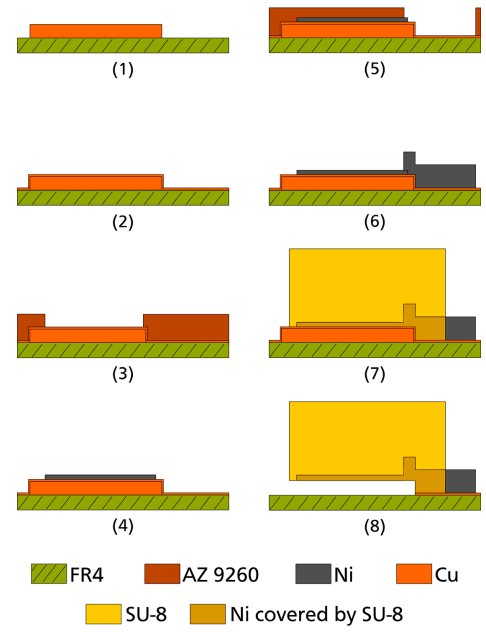

(b)

\subsection{The Fabrication Process}

The actuators are fabricated using surface micromachining, especially UV-lithography and electroforming. The process can be seen in Figure 1b [17]. 4" wafers of printed circuit board (PCB) (FR4) with $15 \mu \mathrm{m}$ of laminated copper serve as substrate. This is cost efficient and provides good structure adhesion due to surface roughness. The copper laminate is used as sacrificial layer and structured by wet etching. First the copper is cleaned of the supplied and often dried out photoresist using acetone and isopropyl, then spin coated with $10 \mu \mathrm{m}$ of $A Z^{\circledR} 9260$ (Clariant Corporation AZ Electronic Materials, Somerville, NJ, USA) high-resolution positive photoresist and patterned using UV-lithography. Development of the photoresist and wet etching using APDS $\left(\mathrm{NH}_{4} \mathrm{~S}_{2} \mathrm{O}_{8}+\mathrm{NH}_{3}+\mathrm{H}_{2} \mathrm{O}_{2}\right)$ structures the sacrificial layer. The meandered heater on the sacrificial layer and the conducting paths on the substrate are fabricated using two consecutive steps of electroforming of nickel. AZ ${ }^{\circledR} 9260$ of $10-30 \mu \mathrm{m}$ thickness is spin coated on the wafer and patterned for use as mold. Nickel is electroplated using an additive free nickel sulfamate bath in the $\mu$ Galv system by M-O-T, ensuring a cost-efficient process. Then $4.4 \mathrm{~mL}$ of SU-8 2025 is cast on the substrate, leveled during softbake and patterned using UV-lithography and a postbake. A final hardbake after release ensures mechanical stability and reduces intrinsic stress. It is done in a convection oven to ensure heating without gradients. The wafers are baked upside-down to prevent the cantilever structures from sticking. 


\section{Optimization of the SU-8 Process for Maximum Mechanical and Temperature Stability}

SU-8 as construction material for electrothermal actuators needs to provide good mechanical and temperature stability which is strongly dependent on the process parameters during fabrication. The influence of the process parameters on selected material properties is known from the literature [18-20], but needs to be investigated in detail, especially with the focus on stability. As SU-8 is a cross-linked thermosetting polymer, the degree of cross-linking and the glass transition temperature are the determinable technical values of interest and are to be optimized in this study.

\subsection{Analysis of SU-8 Fabrication and Deduction of Test Parameters}

The material properties of SU-8 1000 and its processing have been studied by Feng et al. and give an orientation for the analysis of SU-8 2000 [18]. Figure 2 shows the fabrication steps for SU-8 with process parameters. After casting the liquid resist on the substrate, it is dried during softbake. The parameters for material properties are the amount of solvent after softbake, the degree of cross-linking after postbake and the final degree of cross-linking after hardbake.

Figure 2. Fabrication steps of SU-8 with process parameters for investigation.

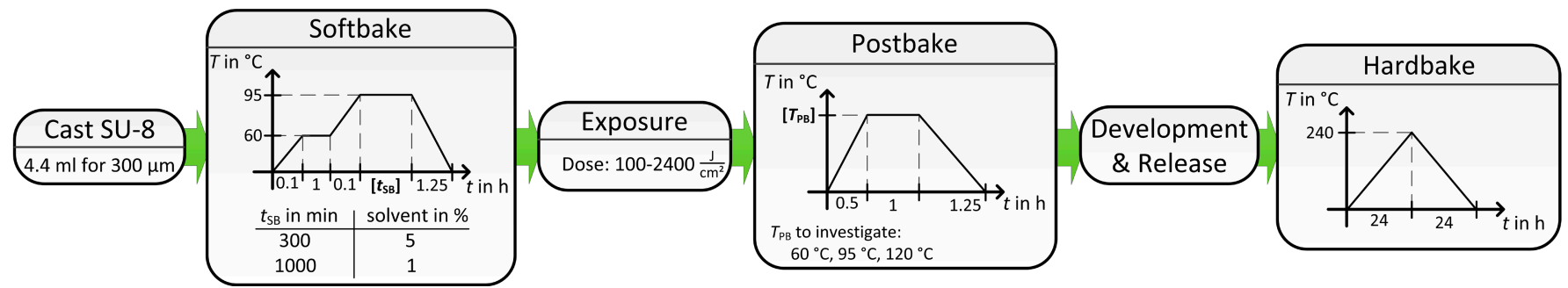

The amount of remaining solvent is adjusted by softbake time and should not exceed $1 \%-5 \%$ of the initial resist mass. The necessary baking time is determined by measuring the weight of a coated wafer during softbake using a micro scale Kern EW 620 (Kern and Sohn, Balingen, Germany) and then calculating the amount of remaining solvent. This results in baking times of $300 \mathrm{~min}$ for $5 \%$ and $1000 \min$ for $1 \%$.

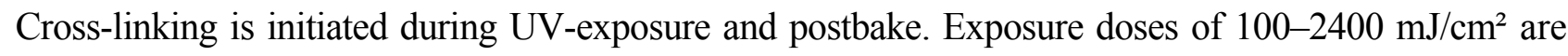
investigated for their influence on the initial cross-linking and structure resolution. Postbake temperatures of $60-120^{\circ} \mathrm{C}$ prove to lead to structures stable enough to be developed [18]. The postbake takes its effect by reaching the desired temperature, so a baking time of $60 \mathrm{~min}$ at maximum temperature is chosen to ensure homogeneous wafer temperature and cross-linking.

Feng et al. showed, that the cross-linking is finalized during hardbake, with the glass transition temperature of SU-8 increasing along the hardbake temperature, reaching its maximum at about $240{ }^{\circ} \mathrm{C}$. Therefore all samples are hardbaked at $240{ }^{\circ} \mathrm{C}$, applying temperature ramps of $10^{\circ} \mathrm{C} / \mathrm{h}$ to avoid gradients of crosslinking that can lead to warped structures [21].

For the experiments, six sets of process parameters above are selected, each set again divided into sections with increased exposure dose of $100-2400 \mathrm{~mJ} / \mathrm{cm}^{2}$. Table 1 sums up the parameters of the study with the parameters $m_{\text {Solv }}$, the remaining solvent in percent of the original mass, and $\vartheta_{\mathrm{PB}}$, the postbake temperature in ${ }^{\circ} \mathrm{C}$. 
Table 1. Sets of process parameters for experiments on material properties of SU-8 with hardbake temperature of $240{ }^{\circ} \mathrm{C}$ for all sets.

\begin{tabular}{ccc}
\hline Set & $\boldsymbol{m}_{\text {Solv }}$ in $\%$ & $\boldsymbol{\vartheta}_{\mathbf{P B}}$ in ${ }^{\circ} \mathbf{C}$ \\
\hline I & 1 & 60 \\
II & 5 & 60 \\
III & 1 & 95 \\
IV & 5 & 95 \\
V & 1 & 120 \\
VI & 5 & 120 \\
\hline
\end{tabular}

\subsection{Degree of Cross-Linking}

To determine the influence of the process parameters on cross-linking and to find the parameter set with the highest degree of cross-linking, samples with the six parameters sets (see Table 1) are analyzed after postbake and again after hardbake by a Fourier Transform Infrared Spectroscopy (FT-IR) procedure presented by Tan et al. [22]. Figure 3 is taken from [22] and shows the FT-IR-spectrum of non-cross-linked SU-8 with the epoxide peak at $914 \mathrm{~cm}^{-1}$ associated with cross-linking of SU-8. As IR-spectroscopy is dependent on varying substrate reflection properties or film thickness, the peak of the aromatic C-C stretch mode at $1608 \mathrm{~cm}^{-1}$ is used as reference, because it does not participate in the cross-linking process. The ratio $I_{914} / I_{1608}$ is a relative measure for the degree of cross-linking.

Figure 3. FT-IR-spectrum of non-cross-linked SU-8 showing the epoxide peak at $914 \mathrm{~cm}^{-1}$ associated with cross-linking of SU-8 and the peak of the aromatic C-C stretch mode at $1608 \mathrm{~cm}^{-1}$ used as reference [22].

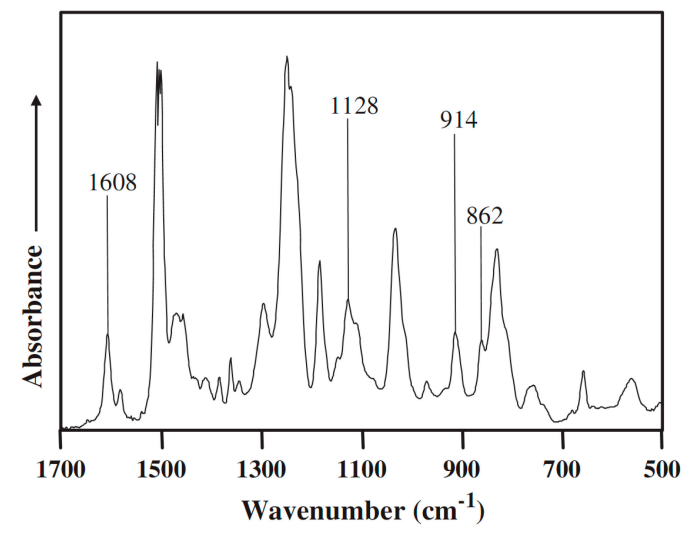

The samples are fabricated by coating single layers of $300 \mu \mathrm{m}$ SU-8 on Si-wafers, even substrate with well-known IR-properties that are discernible from SU-8. Flood exposure is applied to eight subsequent wafer quadrants with increasing dose. Thus, the influence of the dose can be investigated on one wafer. The samples are then examined using a Perkin-Elmer IR-spectroscope.

Figure 4 shows the degree of cross-linking for the six samples as function of the UV-dose after postbake (a) and after hardbake (b). The samples V and VI couldn't be analyzed after hardbake due to layer cracking caused by high intrinsic layer stress. It can be seen in Figure 4a, that cross-linking considerably increases with the postbake temperature, as well as the exposure dose. Compared to this, the remaining solvent (sets with even numbers versus uneven numbers) appears to have no notable 
influence. The results of the hardbaked wafers in Figure $4 \mathrm{~b}$ are leveled compared to the results after postbake and show a high degree of cross-linking. Intrinsic stress was noted for all samples, as a notable curvature occurred after post- and hardbake. The degree of intrinsic stress after postbake increased with the temperature, yet remained stable after hardbake, whereas the samples with lower postbake temperature considerably increased intrinsic stress after hardbake. There appears to be considerable stiffening of the samples during postbake, reducing the influence of the hardbake on instrinsic stress. However, the samples seem to become more brittle with increased baking temperature leading to the cracking of samples $\mathrm{V}$ and VI.

Figure 4. Relative degree of SU-8 cross-linking measured by FT-IR-spectroscopy: (a) After postbake and (b) after hardbake.

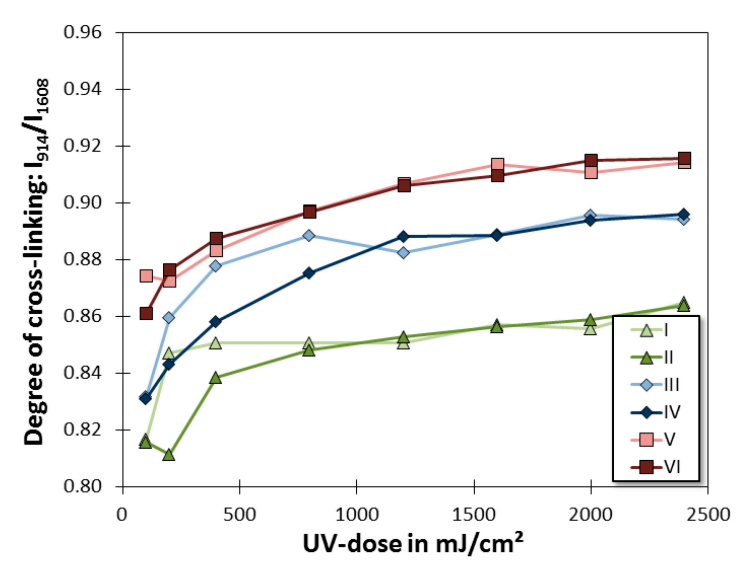

(a)

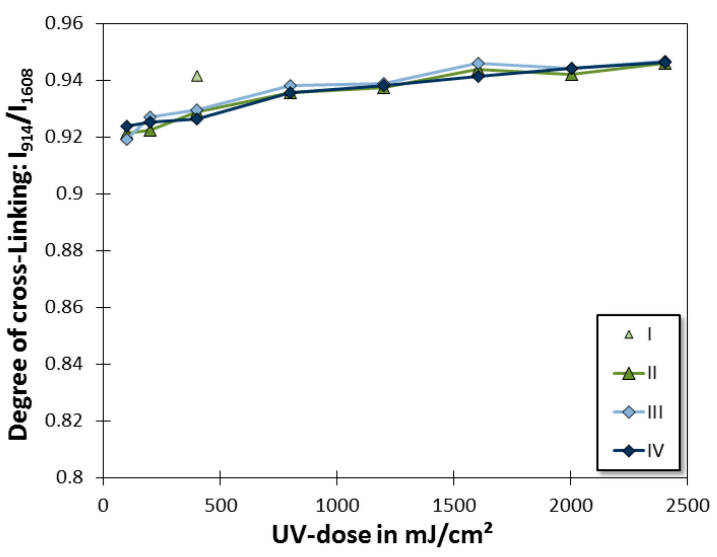

(b)

\subsection{Glass Transition Temperature}

The experiments on cross-linking suggest improved stability with increased baking temperature and leveling by hardbake, yet the highly cross-linked samples appear more brittle. To determine the mechanical stability of the samples under periodical load and possible operation temperatures, the glass transition temperature of samples II and V (see Table 1) is determined using the dynamic-mechanical-analysis (DMA). It allows the determination of the thermo-mechanical material behavior as function of time, temperature and excitation frequency [23]. A sinusoidal force is applied on a rectangular material probe and the resulting deformation is evaluated in regard of amplitude and phase. Thus, the dynamic modulus, loss modulus and glass transition temperature can be calculated. For this experiment, rectangular SU-8 samples of $24 \times 5 \times 0.3 \mathrm{~mm}^{3}$ size are fabricated using the process described in Section 2.2 and completely released from the substrate. They are then analyzed at the Westsächsische Hochschule Zwickau (WHZ) using the DMA $242 \mathrm{C}$ test setup built by NETZSCH Gerätebau GmbH (Selb, Germany) [24,25]. Due to tilting of the wafers during fabrication, the sample thickness is between 300 and $400 \mu \mathrm{m}$ with an average variation of $30 \mu \mathrm{m}$ per sample. This is measured at WHZ using an analog indicator at various sample positions. The samples are then statically preloaded with $0.5 \mathrm{~N}$ to straighten up and a sinusoidal force of $1 \mathrm{~N}$ is applied as dynamic load. Load frequencies of 1,10 and $100 \mathrm{~Hz}$ are applied. The samples are heated from room temperature up to $240{ }^{\circ} \mathrm{C}$ at a constant rate of $1 \mathrm{~K} / \mathrm{min}$. Figure $5 \mathrm{a}$ shows the dynamic modulus as function of temperature for samples II and $\mathrm{V}$ after postbake, Figure $5 \mathrm{~b}$ shows the same after hardbake. 
Figure 5. Dynamic modulus of SU-8 samples II and V (see Table 1) versus temperature (heating rate $1 \mathrm{~K} / \mathrm{min}, 1 \mathrm{~N}$ sinusoidal load): (a) After postbake and (b) after hardbake.

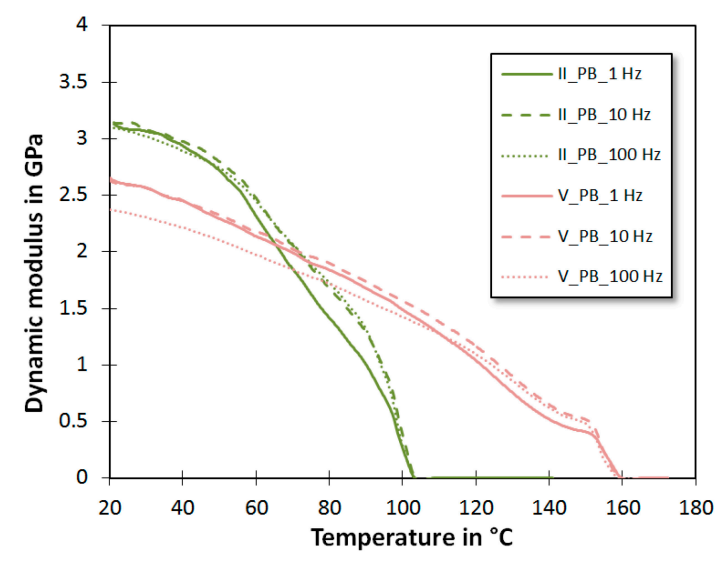

(a)

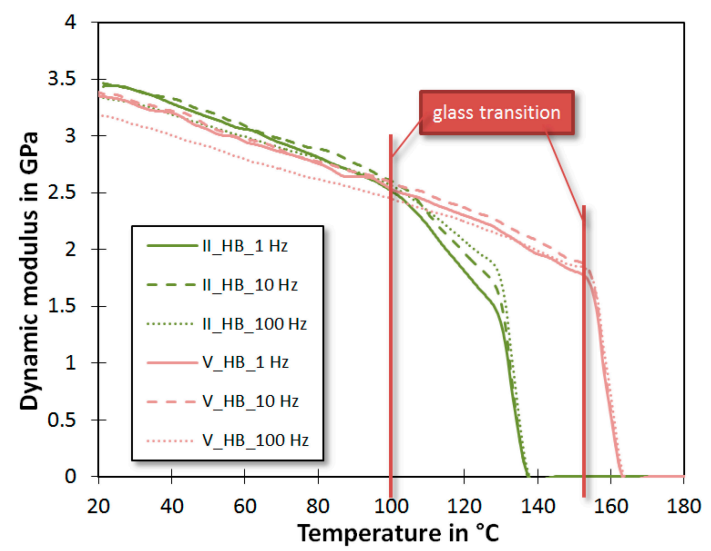

(b)

The measuring errors due to possible tilting of the samples inside the test setup and the measurement error of the indicator have to be considered, yet tendencies and typical material behavior can be seen. The results appear to be fairly independent of the excitation frequency, as the typical behavior is the same for all examined frequencies.

The postbaked samples show a dynamic modulus of up to $3 \mathrm{GPa}$ at room temperature, which is slightly lower than the expected Young's modulus of $3.5 \mathrm{GPa}$ for epoxides and SU-8 [26]. This can be caused by unsufficient cross-linking. The dynamic modulus drops with temperature, as to be expected for a polymer material. The downward bend of the graphs indicates the glass transition, which is not clearly visible for the postbaked samples, but is in the range of the respective postbake temperatures.

The dynamic modulus of the hardbaked samples at room temperature agrees well with the $3.5 \mathrm{GPa}$ from literature and decreases to about $2.5 \mathrm{GPa}$ before glass transition. This confirms the improved thermal stability due to better cross-linking. However, Figure $5 \mathrm{~b}$ shows glass transition temperatures of 100 and $150^{\circ} \mathrm{C}$. In contrast to the results of the IR-experiments, the leveling effect of the hardbake seems not as strong, as glass transition occurs later for samples with higher postbake temperature.

The experiments agree with the IR-measurements in terms of higher baking temperatures leading to improved mechanical stability of SU-8. The glass transition temperature proves to be considerably lower than the hardbake temperature of $240{ }^{\circ} \mathrm{C}$ and contradicts Feng et al. who proposes the glass transition temperature being equal to the hardbake temperature.

\subsection{Discussion}

The experiments indicate that high baking temperatures of SU-8 improve the mechanical properties for long-term stable actuator operation. However, high exposure doses $>1500 \mathrm{~mJ} / \mathrm{cm}^{2}$ and postbake temperatures $>95{ }^{\circ} \mathrm{C}$ considerably reduce the structural resolution, as widening and T-topping of structures arise and small trenches cannot be resolved during resist development. Regarding process time, structural resolution and desired mechanical stability of SU-8, an exposure dose of $1500 \mathrm{~mJ} / \mathrm{cm}^{2}$, a postbake temperature of $95{ }^{\circ} \mathrm{C}$ and a hardbake temperature of $240{ }^{\circ} \mathrm{C}$ are chosen as parameters for further actuator fabrication. 
The results on the glass transition temperature suggest that the permanent actuation temperature of electrothermal actuators made of SU-8 should not exceed $100{ }^{\circ} \mathrm{C}$. This requires further investigation by characterization of the static and dynamic behavior of electrothermal actuators.

\section{Long-term Stability of Electrothermal Actuators and Limits of Operation}

For experiments on electrothermal actuators, samples are fabricated according to the process flow shown in Section 2 and the SU-8 parameter sets III and IV (postbake temperature $=95{ }^{\circ} \mathrm{C}$ ). Both static and dynamic deflections are evaluated using an especially developed test setup. A current source drives the actuators in steps of $1 \mathrm{~mA}$ up to a maximum of $1 \mathrm{~A}$, the voltage is monitored using a HP 34970A (Hewlett-Packard, Palo Alto, CA, USA) digital voltmeter with a resolution of $0.5 \mathrm{mV}$. The driving power can then be calculated. Actuator movement is monitored using an AVT PIKE F-421B CCD camera (Allied Vision Technologies GmbH, Stadtroda, Germany) providing an accuracy $\leq 200 \mathrm{~nm}$. An IR-camera FLIR SC655 (FLIR Systems Inc., Wilsonville, OR, USA) measures the sample temperature from the top. As the emissivity of epoxides such as SU-8 is at about 0.95 , the actuator is opaque for the IR-camera and thus the temperature of the actuator surface measured. Due to the low thermal conductivity of SU- 8 , the heater temperature is $\sim 1.3$ times higher than the surface temperature. In order to determine the maximum operation temperature a static coupled electro-thermo-mechanical FEM-simulation in ANSYS ${ }^{\circledR}$ Workbench (Ansys Inc. Canonsburg, PA, USA) is used. For each temperature measured in these experiments, a simulation of the exact actuator geometry, air gaps, substrate and actuator anchoring is run to match the measured surface temperature. The heater temperature is then taken from the simulation (see also Figure 6). Due to the vertical temperature gradient, there is an out-of-plane deflection, which cannot be measured by the test setup used, but is not of interest in this study.

Figure 6. Averaged static deflection characteristic of electrothermal actuators fabricated using parameter sets III and IV (see Table 1) with measured surface and heater temperatures.

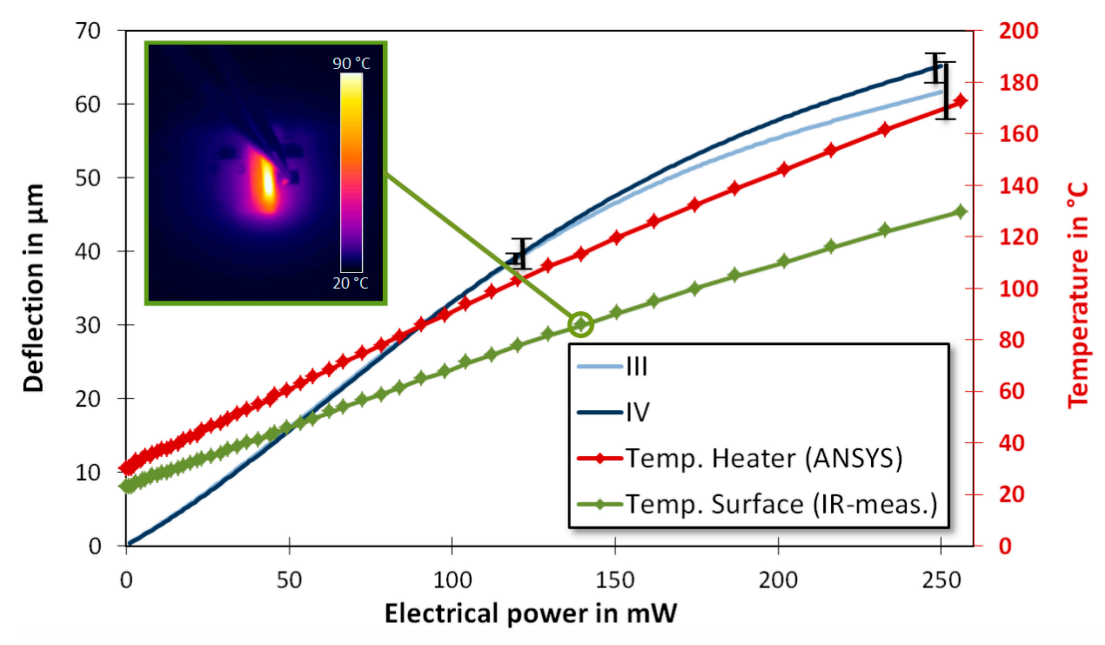

\subsection{Static Actuator Operation}

To estimate the general performance of this design, the static characteristic is recorded. Therefore a gradual current is applied up to an electrical power of $250 \mathrm{~mW}$. The deflection is recorded after holding the electrical power for $15 \mathrm{~s}$ per step to ensure thorough heating of the actuator. Figure 6 shows the static 
characteristics for each parameter set and their maximum operation temperature as function of the electrical power. The graphs are based on 25 data points for five actuators that were curve-fitted using a fifth degree polynomial and then averaged. The standard deviation is exemplary shown at half and full deflection. Only the ascending graph is shown here.

The actuators reach a deflection $>60 \mu \mathrm{m}$ at a power consumption up to $250 \mathrm{~mW}$ and an operation temperature up to $170{ }^{\circ} \mathrm{C}$. Both deflection and maximum operation temperature increase proportionally to the electrical power up to about $100 \mathrm{~mW}$, where a knee appears in the deflection. Until then, the deflection remains stable for the heating time. For higher powers, a backwards drift of the actuator can be noted. This is supposed to be caused by softening of the heated beam with temperature (see Figure 5) and thereby reduced actuation force. Plastic deformation is expected for temperatures $>100{ }^{\circ} \mathrm{C}$, too. The permanent operating point of the actuator is to be expected in the $120 \mathrm{~mW}$ range and will be examined closer in the following sections.

\subsection{Dynamic Actuator Operation}

Further samples of parameter set IV are excited by a rectangular electrical power of gradually increasing amplitude at a frequency of $0.1 \mathrm{~Hz}$. The electric input power, the amplitude, the offset drift and the operating temperature are monitored under a cycle of constant operation for 20 min followed by a $20 \mathrm{~min}$ break. The electrical input power is gradually increased from 100 to $200 \mathrm{~mW}$. The duration of the experiments was between 1.5 and $2.5 \mathrm{~h}$ per step. The results can be seen in Figure 7.

Figure 7. Dynamic characteristic of electrothermal actuators: Electrical input power, amplitude, offset drift and maximum operation temperature over actuation time.

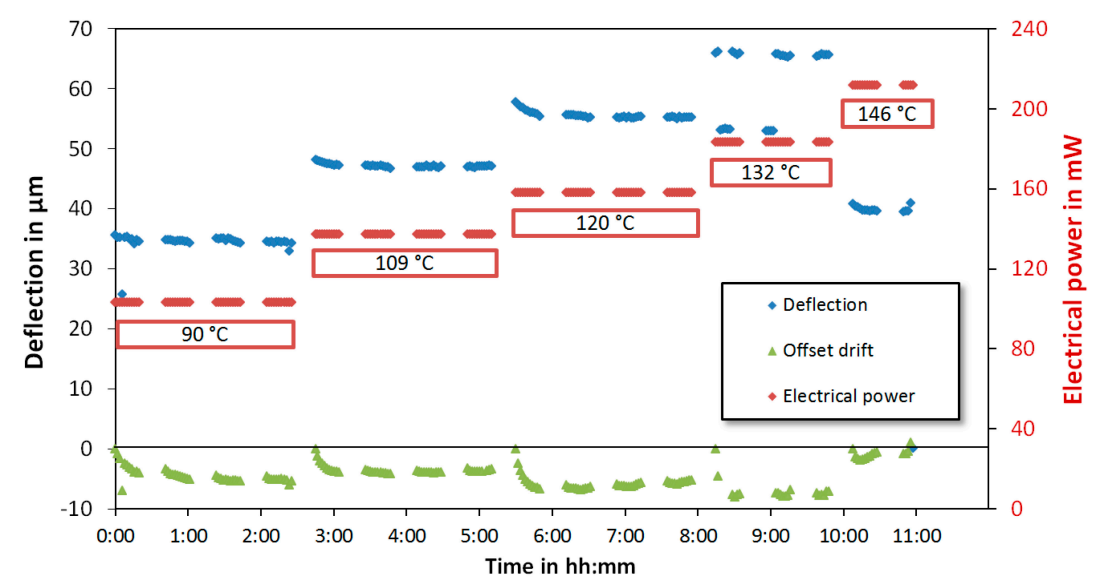

Deflections up to $55 \mu \mathrm{m}$ were reached for a driving power up to $160 \mathrm{~mW}$, reaching a maximum operating temperature up to $120^{\circ} \mathrm{C}$. Beyond those values, no reproducible operation was possible, because occasional drop or significant reduction of deflection occurred with increasing damage of the actuator until failure beyond $200 \mathrm{~mW}$. The experiment shows that stable actuator operation is possible for permanent operating temperatures up to $120{ }^{\circ} \mathrm{C}$. This agrees very well with the glass transition temperatures measured in Section 3. A significant offset drift against the direction of actuation occurs for every power step. The drift is defined as the difference of maximum and minimum deflection of the current duty cycle subtracted from the first duty cycle of the current power step. Thus, just the drift caused by the current power step is monitored. The reason for the drift was not determined so far, but 
slow, yet unwanted heating of the actuator surroundings and the cold beam, as well as the evaporation of humidity in SU-8 are found as explanations in the literature [27].

Only if the offset drift and the deflection converge on a fixed value over time, a long-term stable operation can be assumed. Therefore a study of operation under the cycle of $20 \mathrm{~min}$ actuation followed by a $20 \mathrm{~min}$ break was conducted at $100 \mathrm{~mW}$. This causes a maximum operation temperature of $78^{\circ} \mathrm{C}$, which is below the glass transition temperature. It avoids thermal overload of SU-8, but makes long-term effects visible. Figure 8 shows the result.

An average deflection of $34.6 \mu \mathrm{m}$ at a standard deviation of $0.24 \mu \mathrm{m}$ can be seen. The offset drift of up to $6 \mu \mathrm{m}$ corresponding to about $20 \%$ of the actuator deflection is notable here as well. After a burn-in phase of $2 \mathrm{~h}$, this shift remains constant over the remaining $8 \mathrm{~h}$ of operation. An asymptotic convergence of the shift can be seen when resuming operation after a break. Being considered stable after $10 \mathrm{~h}$ of operation and 2400 duty cycles the experiment was stopped.

Figure 8. Dynamic characteristic for long-term operation at $100 \mathrm{~mW}$ and a maximum temperature of $80^{\circ} \mathrm{C}$ : Electrical input power, amplitude and offset drift versus actuation time.

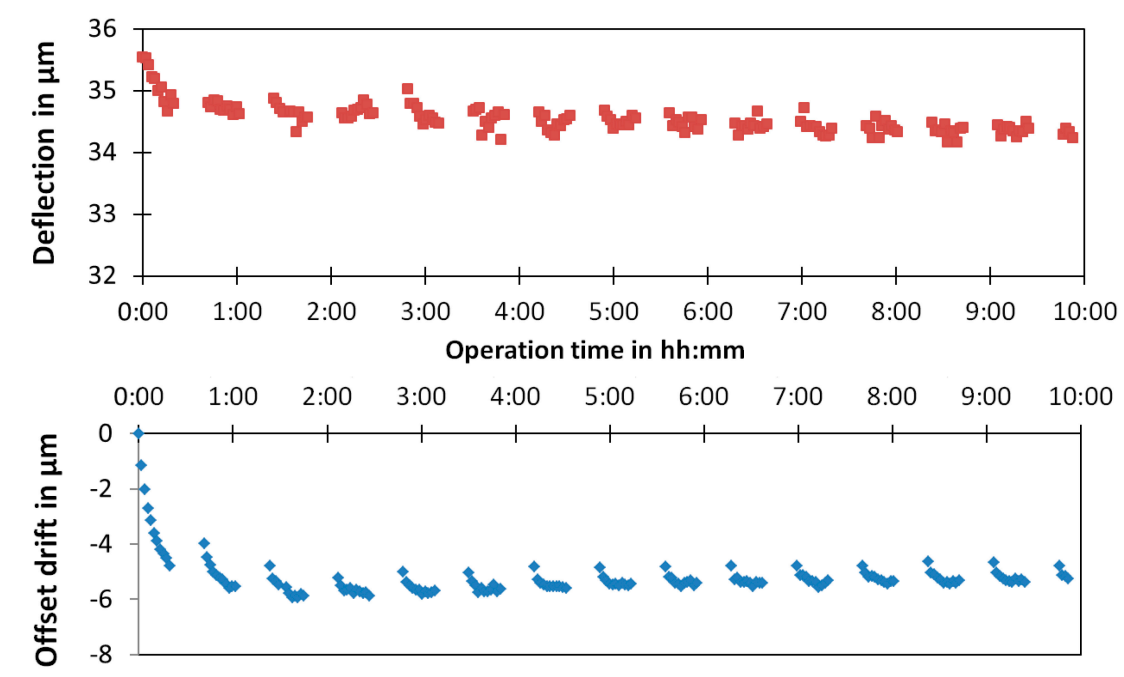

\section{Conclusions and Outlook}

In this work the suitability of SU-8 2000 with $300 \mu \mathrm{m}$ thickness as a construction material for electrothermal actuators has been examined. The mechanical and thermal properties of SU- 8 have been analyzed for six different sets of various process parameters. The degree of cross-linking and the dynamic modulus have been measured and compared using IR-FT and the DMA. It has been found, that the amount of solvent after softbake can be neglected regarding the material properties. The exposure dose should exceed $1500 \mathrm{~mJ} / \mathrm{cm}^{2}$ to provide a thorough initiation of cross-linking. The postbake temperature has a clear influence on the dynamic modulus and the glass transition temperature of SU-8, whereas the hardbake considerably levels the effect of the process history. A high degree of cross-linking as well as a low drop of the dynamic modulus over temperature (30\%) and glass transition temperatures of $100-140{ }^{\circ} \mathrm{C}$ have been measured for hardbaked SU- 8 structures regardless of previous process parameters.

Finally electrothermal actuators made of SU- 8 have been fabricated and tested. Single-sided use of these actuators proved to be possible and stable for up to $10 \mathrm{~h}$ and operation temperatures up to $120{ }^{\circ} \mathrm{C}$. This correlates well with the determined glass transition temperature of SU-8 and recommends this 
parameter as criterion to evaluate the suitability of polymers for electrothermal actuators. Temperatures exceeding this limit led to plastic deformations and actuator failure. An offset drift of up to $20 \%$ occurs during actuation, but converges after a burn-in phase of about two hours.

In future work, the SU-8 process should be optimized in order to reach the glass transition temperature proposed by Feng et al. The current actuator design can be improved by increasing the air gap towards the substrate, or completely removing the substrate, to reduce the offset drift due to unwanted heating and improve the overall actuator performance. Dependence of air humidity on the actuator performance is not examined but can lead to a further understanding of the drift. Finally, high temperature polymers such as PEEK need to be evaluated as an alternative to SU-8 for better temperature stability and higher operation temperatures. The behavior and long-term stability of electrothermal actuators under a permanent mechanical load has not been studied so far but is a next important step to judge the full potential of this actuator technology.

\section{Acknowledgments}

The authors would like to thank Technische Universität Darmstadt and Westsächsische Hochschule Zwickau for funding this work.

\section{Author Contributions}

Dipl.-Ing Thomas Winterstein designed the experiments concerning SU-8, conducted the IR-spectroscopy and wrote the manuscript. Dr.-Ing. Matthias Staab designed electrothermal actuators and developed the fabrication process. Dipl.-Ing. Christian Nakic fabricated and characterized electrothermal actuators. Prof. Dr.-Ing. Schlaak supervised the work and reviewed the manuscript. Hans-Jürgen Feige and Prof. Dr. Jürgen Vogel designed and conducted the dynamic-mechanical-analysis and helped interpreting the results.

\section{Conflicts of Interest}

The authors declare no conflict of interest.

\section{References}

1. Park, D.S.W.; Nallani, A.K.; Cha, D.; Lee, G.S.; Kim, M.J.; Skidmore, G.; Lee, J.B.; Lee, J.S. A sub-micron metallic electrothermal gripper. Microsyst. Technol. 2010, 16, 367-373.

2. Lee, J.S.; Park, D.S.W.; Nallani, A.K.; Lee, G.S.; Lee, J.B. Sub-micron metallic electrothermal actuators. J. Micromech. Microeng. 2005, 15, 322-327.

3. Carlson, K.; Andersen, K.N.; Eichhorn, V.; Petersen, D.H.; Mølhave, K.; Bu, I.Y.Y.; Teo, K.B.K.; Milne, W.I.; Fatikow, S.; Bøggild, P. A carbon nanofibre scanning probe assembled using an electrothermal microgripper. Nanotechnology 2007, 18, 345501.

4. Akiyama, T.; Staufer, U.; de Rooij, N.F.; Lange, D.; Hagleitner, C.; Brand, O.; Baltes, H.; Tonin, A.; Hidber, H.R. Integrated atomic force microscopy array probe with metal-oxide-semiconductor field effect transistor stress sensor, thermal bimorph actuator, and on-chip complementary metal-oxide-semiconductor electronics. J. Vac. Sci. Technol. B 2000, 18, 2669-2675. 
5. Ebefors, T.; Kälvesten, E.; Stemme, G. Dynamic actuation of polyimide V-groove joints by electrical heating. Sens. Actuators A Phys. 1998, 67, 199-204.

6. Nakic, C.; Staab, M.; Dörr, R.; Schlaak, H.F. Polymer in-plane electrothermal actuators fabricated by UV-lithography versus micro-milling of PEEK. In Proceedings of 14th International Conference on New Actuators and 8th International Exhibition on Smart Actuators and Drive Systems, Bremen, Germany, 23-25 June 2014; pp. 398-401.

7. Kopka, P.; Hoffmann, M.; Voges, E. Coupled U-shaped cantilever actuators for $1 \times 4$ and $2 \times 2$ optical fibre switches. J. Micromech. Microeng. 2000, 10, 260-264.

8. Chronis, N.; Lee, L.P. Electrothermally activated SU-8 microgripper for single cell manipulation in solution. J. Microelectromechan. Syst. 2005, 14, 857-863.

9. Lee, J.S.; Park, D.S.; Nallani, A.K.; Yonghao, C.; Skoyles, A.; Lee, J.B. High-Aspect Ratio Metallic Nano Grippers. In Proceedings of International Conference on Nano/Micro Engineered and Molecular Systems, Zhuhai, China, 18-21 January 2006; pp. 682-686.

10. Mackay, R.E.; Le, H.R.; Keatch, R.P. Design optimisation and fabrication of SU-8 based electro-thermal micro-grippers. J. Micro-Nano Mechatron. 2011, 6, 13-22.

11. Qui, J.; Lang, J.H.; Slocum, A.H.; Strumpler, R. A high-current electrothermal bistable MEMS relay. In Proceedings of 6th IEEE International Conference on Micro Electro Mechanical Systems, Kyoto, Japan, 23 January 2003; pp. 64-67.

12. Staab, M.; Schlaak, H.F. Novel electrothermally actuated magnetostatic bistable microrelay for telecommunication applications. In Proceedings of 24th IEEE International Conference on Micro Electro Mechanical Systems, Cancun, Mexico, 23-27 January 2011; pp. 1261-1264.

13. Girbau, D.; Roldan, A.M.; Pradell, L. RF MEMS switches based on the buckle-beam thermal actuator. In Proceedings of 33th European Microwave Conference, Munich, Germany, 9 October 2003; Volum 2, pp. 651-654.

14. Winterstein, T.; Schlaak, H.F. Normally latched linear inchworm drive with electrothermal actuation for fluidic applications. In Proccedings of ACTUATOR12, 13th International Conference on New Actuators and 7th International Exhibition on Smart Actuators and Drive Systems, Bremen, Germany, 18-20 June 2012; pp. 713-716.

15. Lorenz, H.; Laudon, M.; Renaud, P. Mechanical characterization of a new high-aspect-ratio near UV-photoresist. Microelectron. Eng. 1998, 41-42, 371-374.

16. Staab, M.; Schlaak, H.F. Indirectly Heated Electrothermal Actuator for a Magnetostatic Bistable Micro Actuator System. In Proceedings of 12th International Conference on New Actuators and 6th International Exhibition on Smart Actuators and Drive Systems, Bremen, Germany, 14-16 June 2010; pp. 356-360.

17. Winterstein, T.; Schlaak, H.F. Electrothermal pseudo bimorph actuators made of SU-8 with improved mechanical performance. In Proceedings of ACTUATOR14, 14th International Conference on New Actuators and 8th International Exhibition on Smart Actuators and Drive Systems, Bremen, Germany, 23-25 June 2014; pp. 609-612.

18. Feng, R.; Farris, R.J. Influence of processing conditions on the thermal and mechanical properties of SU-8 negative photoresist coatings. J. Micromech. Microeng. 2003, 13, 80-88.

19. Barber, R.L.; Ghantasala, M.K.; Divan, R.; Vora, K.D.; Harvey, E.C.; Mancini, D.C. Optimisation of SU-8 processing parameters for deep X-ray lithography. Microsyst. Technol. 2005, 11, 303-310. 
20. Kouba, J.; Bednarzik, M.; Engelke, R.; Ahrens, G.; Miller, H.; Haase, D. Optimizing SU-8 resist to fabricate micro-metallic structures. Solid State Technol. 2006, 49, 39-44.

21. Sameoto, D.; Tsang, S.H.; Foulds, I.G.; Lee, S.W.; Parameswaran, M. Control of the out-of-plane curvature in SU-8 compliant microstructures by exposure dose and baking times. J. Micromech. Microeng. 2007, 17, 1093-1098.

22. Tan, T.L.; Wong, D.; Lee, P.; Rawat, R.S.; Springham, S.; Patran, A. Characterization of chemically amplified resist for X-ray lithography by Fourier transform infrared spectroscopy. Thin Solid Films 2006, 504, 113-116.

23. Ehrenstein, G.W.; Riedel, G.; Trawiel, P. Thermal Analysis of Plastics: Theory and Practice; Carl Hanser Verlag GmbH Co KG: Munich, Germany, 2012.

24. Vogel, J.; Feige, H.-J.; Saupe, J.; Schubert, S.; Grimm, J. In Experimental analysis of thermo-mechanical material properties of photosensitive polymers. In Proceedings of 11th Youth Symposium on Experimental Solid Mechanics, Brasov, Romania, 30 May-02 June 2014; pp. 61-66.

25. Vogel, J.; Feige, H.-J.; Saupe, J.; Schubert, S.; Grimm, J. Mechanical material characterization of photosensitive polymers. Microsyst. Technol. 2014, 20, 1975-1979.

26. Robin, C.J.; Vishnoi, A.; Jonnalagadda, K.N. Mechanical behavior and anisotropy of spin-coated SU-8 thin films for MEMS. J. Microelectromech. Syst. 2014, 23, 168-180.

27. Wouters, K.; Puers, R. Diffusing and swelling in SU-8: Insight in material properties and processing. J. Micromech. Microeng. 2010, 20, 095013.

(C) 2014 by the authors; licensee MDPI, Basel, Switzerland. This article is an open access article distributed under the terms and conditions of the Creative Commons Attribution license (http://creativecommons.org/licenses/by/3.0/). 